\title{
"Señora, no espere que un día de hospital cure 40 años de mala vida": morte, emoções e fronteira
}

\section{"Mrs., don't expect a day at the Hospital will heal 40 years of bad life": death, emotions and borderlands}

José Miguel Nieto Olivar*

*Universidade de São Paulo - São Paulo, SP, Brasil

escreve.ze@gmail.com

https://orcid.org/0000-0002-7648-7009 


\title{
Resumo
}

Este artigo é produto de mais de sete anos de pesquisa sobre gênero, sexualidade, dinheiro, Estado e fronteiras na cidade de Tabatinga (AM), na tríplice fronteira entre o Brasil, a Colômbia e o Peru. Proponho uma reflexão sobre a produção emocional da fronteira e sobre a fronteira como materialização performativa de determinadas gramáticas emocionais. Através da narrativa fortemente implicada no adoecimento e morte da Carmelo, "patrona" de um prostíbulo transfronteiriço naquela cidade, argumento que adoecer e rumar-se à morte implica para algumas pessoas um doloroso processo de sujeição e periferização, atravessado por uma testagem derradeira dos circuitos e gramáticas afetivas através das quais se produziu a vida. Tal processo implica atualizações e performatizações de emoções que podem estar relacionadas com a construção mito-conceitual da Fronteira.

Palavras-chave: Amazônia; adoecimento; gênero; cuidado.

\begin{abstract}
This article is a result of over 7 years of research on gender, sexuality, money, State and borderlands in Tabatinga city (AM), at the triple border region between Brazil, Colombia and Peru. I propose a reflection on the emotional production of the broder/ frontier and about it as a performative materialization of specific emotional grammars. Through the strongly implicated narrative of the illness and death of Carmelo, a transborder brothel "madam" in that town, I claim that to sicken and direct into death implies in a painful process of submission and peripherization for some people, crossed by a final testing of circuits and affective grammars through which life built itself. Such process implies in effectuation and enacting of emotions that can be related to the myth-conceptual construction of Border.
\end{abstract}

Keywords: Amazon; illness; gender; care. 


\section{Introdução ${ }^{1}$}

Esse artigo é produto de um processo de pesquisa antropológica de mais de sete anos, sobre gênero, sexualidade, dinheiro, Estado e fronteiras, que teve como site principal a cidade de Tabatinga (AM), na tríplice fronteira entre o Brasil, a Colômbia e o Peru. ${ }^{2}$ Nesses anos, boa parte da minha pesquisa esteve focada na compreensão da prostituição e dos mercados sexuais transfronteiriços e teve como um dos seus recortes empíricos específicos um prostíbulo colombiano nessa cidade brasileira.

A partir desse marco, proponho aqui refletir sobre a produção emocional da fronteira (território, mito-conceito (Serje, 2005) e sobre a fronteira como materialização performativa de uma determinada gramática emocional que pode ser pensada como ramificações articuladas de sentimentos associados à coragem, de um lado, e à pena, do outro. Isto é, argumentarei que fronteira, como processo e mito-conceito fortemente associados à modernidade, indica uma gramática emocional de territorialização e localização afetiva da alteridade.

O objeto empírico a partir do qual formulo essas reflexões é o adoecimento e morte da minha amiga Carmelo, "patrona" do prostíbulo acima mencionado. Através da narrativa fortemente implicada do adoecimento e morte da Carmelo, argumento que adoecer e rumar à morte implica para algumas pessoas não apenas um processo sociobiológico (Elias, 1989, p. 52) de intensificação da precariedade e da dependência, mas um doloroso processo de sujeição e periferização, atravessado por algo como uma testagem derradeira dos circuitos e gramáticas

1 Agradeço à Fapesp e ao Núcleo de Estudos de Gênero Pagu (Unicamp) que garantiram condições de possibilidade para a realização das pesquisas e do estudo. Ao pessoal da Universidad Nacional de Colombia, sede Leticia, que durante esses anos me acolheram e se transformaram em interlocutores e amigos. À Flavia Melo, Lindomar Albuquerque, Silvana Nascimento, Fábio Candotti, Guilherme Passamani que durante esses anos se transformaram em parceirxs de pesquisa e grandes amigxs. A Luiza Terassi e Mário Carneiro que me acompanharam em parte dessa jornada. Ao pessoal de Horizontes Antropológicos, revista da minha primeira e mais amada casa no Brasil: PPGAS/UFRGS. A Leticia Cao Ponso pela revisão cuidadosa e alimentícia de sempre. A Márcia, companheira de antropologias e amores.

2 Pesquisas realizadas principalmente com financiamento da Fapesp entre 2010 e 2017, desde o Núcleo de Estudos de Gênero Pagu, da Unicamp (Fapesp 2013/26926-2). Contei também com recursos do CNPq (através da minha participação num projeto da Dra. Adriana Piscitelli) e da Funcamp. Realizei mais de 14 meses não contínuos de etnografia nessa tríplice fronteira. 
afetivas através das quais se produziu essa vida. ${ }^{3}$ No caso estudado, tal processo implica atualizações e performatizações de emoções que, na análise, podem estar relacionadas com a construção mito-conceitual (Serje, 2005) da Fronteira: pena, solidão, lástima, compaixão.

Carmelo foi a minha principal interlocutora no trabalho de campo etnográfico que realizei entre 2011 e 2015 nessa cidade; ela era uma mulher colombiana, branca, "arepera" (lésbica), "machorra" (masculinizada), "conservadora", dona de um prostíbulo transfronteiriço, que no início dos anos 1980 migrou do centro do país para a cidade de Leticia (Colômbia). Este artigo conecta eventos, perspectivas, narrativas e posições, corpos e seus processos, que têm a ver com marginalidades e fronteiras, com abjeções e "zonas de indeterminação" do legitimável (Butler, 2004), com práticas de ruptura e reorganização das formas do parentesco, do gênero e dos afetos, e busca entender as formas como afetos e emoções se constituem num território de passagem para a produção da fronteira através das perturbações (Duarte, 1994, 1998), o cuidado e a morte.

$\mathrm{O}$ que a morte dela tem a nos dizer sobre a forma como determinadas emoções estão implicadas na produção da fronteira? O que farei a seguir será, primeiro, apresentar um marco teórico mínimo para a discussão que conecta fronteiras, emoções e morte. A partir daí reconfiguro uma narrativa evocativa (Skoggard; Waterston, 2015) do adoecimento e morte da Carmelo através destas gramáticas, analisando os processos de precarização e periferização presentes, bem como as tensões de (des)sujeição.

\section{Fronteira, emoções e morte}

Tentando avançar num conhecimento antropológico sobre a fronteira, Margarita Serje (2005) estuda o processo de construção discursiva e conceitual dos

3 Uma primeira versão deste texto foi apresentada no Núcleo de Antropologia Simétrica do PPGAS do Museu Nacional/UFRJ, em 13 de maio de 2016; versões posteriores foram apresentadas no VI Congresso da Associação Portuguesa de Antropologia em junho de 2016 e na Cátedra IMANI: Encuentros entre la Amazonia, América y Europa, Fronteras Sin Muros Ni Hegemonías, organizada pelo Grupo de Estudios Transfronterizos GET da Universidad Nacional de Colombia em 14 de setembro de 2018. Agradeço aos/às professores/as que tornaram possível participar nesses espaços. 
"territórios selvagens", das fronteiras e periferias do Estado-nação colombiano. Serje mostra a forte dimensão mítica, autorreprodutiva e mistificadora do conceito de Fronteira, ligado de maneira reiterativa às imagens de territórios vazios e de populações selvagens, de ameaças e de riquezas, e à ideia dos "heróis de fronteira" (aqueles desbravadores...). O trabalho da autora demonstra como esse sistema é atualizado contemporaneamente em termos de políticas públicas, de narrativas midiáticas, de ações humanitaristas e de pesquisas sociais. "El concepto de Frontera tiene un efecto reiterativo. Su retórica es especialmente eficaz para naturalizar los supuestos en los que se fundamenta" (Serje, 2005, p. 135). Se no caso de Serje a noção de fronteira diz respeito a frentes de expansão, agrícolas, econômicas, sua análise alcança também algumas fronteiras internacionais. Principalmente, como na Amazônia, onde fronteiras coloniais, imperiais, internacionais e fronteiras internas, entre outras muitas fronteiras, se conjugam e coproduzem.

Em tradições antropológicas como as mobilizadas por Marshall Sahlins (1985) ou Michael Taussig (1993), o mito está longe de ser um construto ideológico, mental ou lateral à realidade. $\mathrm{O}$ mito está associado a estruturas sociais de conhecimento e de sentido, às condições de possibilidade da história e, por isso, às condições sociais de produção de verdade e de existência em determinados âmbitos sociais. Em termos de Sahlins (1985), a realidade mítica existe nos "esquemas culturais" ou esquemas de sentido, nas conjunturas sociais, nos corpos e ações práticas das culturas e seus sujeitos, e é permanentemente atualizada nessas práticas. E é, justamente nessa práxis corporal, relacional, afetiva que, como afirma o autor, toda estrutura mítica-conceitual é colocada em risco.

Enquanto mito e enquanto conceito, então, a fronteira é mobilizada por sistemas emocionais e afetivos específicos, e seu processo de atualização efetua ou contraefetua tais emoções. Para esse caso, recupero um par emocional muito presente em teorias e narrativas de fronteira, que pode ser colocado em termos de coragem e pena, e que tem seu correlato em duas posições de poder maioritárias com relação à fronteira: a exploração, de um lado, e a civilização, do outro. Essa gramática emocional, assim, diz respeito à dupla perspectiva das "terras selvagens" (ou dos limites internacionais) como ermas e como terríveis ameaças superpovoadas de monstros (ou de estrangeiros ávidos que esperam do outro lado); como fatalmente carentes e abandonadas (ou como vizinhas de 
países pobres e problemáticos); e como possuidoras de uma riqueza inimaginável (ou como porta de entrada da riqueza "sovinada"4 da nação-nós).

Por um lado, temos uma tradição clássica dos estudos de fronteiras (internas) [front, frontiers], por exemplo, que presta atenção e mobiliza dimensões emocionais e afetivas relacionadas com a aventura, com a conquista, a expansão e a capacidade -fundamentalmente antropocêntrica, individualista e masculina - de encarar novos mundos e desafios. Emergem emoções épicas como a coragem, o destemor, a excitação e o desejo pelo risco, pela posse, pela aventura e pela sobrevivência. É o lugar dos "heróis de fronteira". Essa narrativa encontra uma conexão fácil e direta de atualização através da exaltação da ideia de "perigo". Tem lugar nas performatividades associadas à segurança pública e à defesa nacionais nos limites internacionais e se materializa de forma muito concreta em importantes investimentos políticos, econômicos e desejantes do Estado. ${ }^{5}$

Inclusive, essa gramática emocional do front é analisada desde suas contrapartes de poder: 0 ato heroico (Turner, 1993) [coragem, heroísmo] e o sofrimento causado por ele (Martins, 1997) [pena, compaixão, solidariedade]. Nessa linha, a pena, a compaixão e a solidariedade se tornam também um componente central das gramáticas emocionais associadas à fronteira, implicando um profundo deslocamento de perspectiva - que coloco em termos dos seus nomes históricos: da exploração à civilização. Para isso me remeto pontualmente à análise recente de Flávia Melo da Cunha (2017) sobre a produção dos discursos de pena e perigo na fronteira. A mitologia conceitual da fronteira como um lugar "selvagem" se traduz, também, em toda uma gramática da necessidade da segurança pública, toda uma demanda multilocal de estratégias e presenças da defesa, e em demandas e legislações de indenização econômica aos trabalhadores federais (e em alguns casos estaduais) que atuam em territórios da

4 Uso "sovinar" aqui como é comum na região do Alto Rio Negro e em outros lugares da Amazônia: mesquinhar, guardar para si, não compartilhar o que é devido, tornar próprio algo que não o é, truncar o fluxo das trocas.

5 De forma correlata a essa leitura, mas modificando noções de fronteira e perspectivas de análise, estudos sobre "atravessadores" de fronteiras ressaltam também emoções associadas ao desejo pela mobilidade ou migração, ao risco, à aventura, à intersticialidade e hibridação. Ver trabalhos sobre táticas para atravessar fronteiras (Dias, 2015, por exemplo), ou sobre agência através de fronteiras internacionais (Piscitelli, 2013), ou, em outro sentido ainda, sobre fronteira como teoria de mestiçagem (Anzaldua, 2012). 
fronteira internacional. ${ }^{6}$ Em outro lugar (Olivar, 2015) mostrei como no caso da associação entre políticas de fronteirização contemporâneas e políticas de enfrentamento ao tráfico de pessoas a região amazônica e as fronteiras são construídas como espaços de especial vulnerabilidade especialmente para as mulheres (e mais ainda para as jovens indígenas), de múltiplas carências e demandantes de altas doses de compaixão e solidariedade. A fronteira, assim, aparece associada não somente à ideia colonial de "vazio" a ser desbravado, e à de periferia a ser vigiada, controlada, temida e sofrida, mas ao sentimento pós-colonial de benevolência e de urgente assistência humanitária a territórios explorados. ${ }^{7} \mathrm{O}$ desamparo da distância, do convívio com o "selvagem" (seja esse nativo, colonizador ou estrangeiro), vincula a fronteira ao medo e à enorme dificuldade (pena) de habitar e trabalhar nela.

Nessa gramática emocional e afetiva, a fronteira é constantemente atualizada, não apenas na dimensão imaginária e conceitual do mito, mas na materialidade do território, das leis e normatividades, dos orçamentos disponibilizados, da presença institucional em corpos, máquinas e prédios, etc. É na ação conectada de forma criativa com essas gramáticas emocionais que a fronteira encontra, para usarmos a lógica de Judith Butler (1998), sua condição performativa: reiteração, repetição, norma e abjeção.

Skoggard e Waterston (2015) explicam como, de formas diversas, emoções e afetos estiveram sempre presentes no trabalho da antropologia e foram centrais na definição de alguns dos seus conceitos-chave. Desde o clássico trabalho de Mauss (1979), até conexões mais contemporâneas sobre afetos (incluindo um recente debate norte-americano ao redor da Affect Theory (ver Martin, 2013; Skoggard; Waterston, 2015; entre outros), passando por trabalhos referenciais como o de Abu-Lughod e Lutz (1990) e a importante crítica de Crapanzano (1994), ou o trabalho de Le Breton (2013). Assumo assim uma perspectiva relacional das emoções e dos afetos, evitando pensá-los como

6 "Auxílio Penosidade de Fronteira" foi uma reivindicação de professores federais em 2015 e serve a Cunha como mote para sua análise.

7 Fassin (2011) mostra como a "razão humanitária" traz consigo uma construção moral-afetiva de gestão da benevolência naqueles que "ajudam". Essa construção está associada a sentimentos como a compaixão, e se constitui em uma "emoção de demarcação de status" (Coelho; Pardo, 2018) pois é, fundamentalmente, um sentimento que (re)produz assimetrias: afinal, quem pode sentir compaixão e por quem? Para uma abordagem das regras sociais da compaixão, ver Clark (1997). 
totalidades definíveis e desde chaves dicotômicas de explicação (natureza-cultura, corpo-mente, emoção-razão, feminino-masculino), ou no sentido de verdades profundas atreladas a dimensões espirituais, psicológicas ou biológicas do ser humano. No sentido proposto por Abu-Lughod e Lutz (1990) e retomado no Brasil por Coelho e Rezende (2011) (Rezende; Coelho, 2010; Coelho; Pardo, 2018), me interessa pensar em termos de gramáticas emocionais que são colocadas em jogo em determinados momentos, que são socialmente produzidas e que têm efeitos concretos, micropolíticos, sobre a vida, os corpos, os espaços, etc. Igualmente, assumo uma perspectiva performativa e não expressiva das emoções (Butler, 1998), que tem na ideia de afetar sua condição relacional (Le Breton, 2013). Nesse sentido, retomo a ideia de "circuitos de afetos", que de modos diferentes, mas relacionáveis, atravessa trabalhos de Butler (2010) e de Safatle (2015), e que diz respeito à restituição política de vínculos de codependência e de persistência da vida perante marcos de guerra e desamparo. Nesse sentido, a noção de "afeto", bem como a nomeação de determinadas emoções, apareceram de forma êmica no meu campo.

Dessa forma, entendo a fronteira desde a chave das gramáticas emocionais a ela atreladas na circularidade dos discursos de exploração e civilização à qual me referi acima. No limite, me pergunto se fronteira, antes que um território específico, e antes inclusive que sua imaginação nacional como limite, não serve ela própria como nominação fertilizante para toda uma gramática emocional performativa sobre diferença, relação e potência, altamente materializada e materializável (em corpos, territórios, paredes, papéis, etc.), que pode ser facilmente transportada (com os efeitos reificantes descritos por Serje) através de nossas cartografias analíticas.

Mas no meio dessa gramática mito-histórica, conceitual e política, encontramos um corpo atrelado a uma fronteira específica, que envelhece, adoece e morre, cuja morte diz sobre a fronteira e seus afazeres, e sobre o qual se tece coletivamente uma narrativa de abandono, pena e solidão. O corpo e a morte da "patroa" do prostíbulo.

Este artigo remete ao trabalho de Claudia Fonseca (2004) chamado "A morte de um gigolô: fronteira da transgressão e sexualidade nos dias atuais". O trabalho de Claudia opera um movimento fundamental: aborda a prostituição desde outro campo que não os estudos de sexualidade. Colocando a sexualidade em suspenso - como perspectiva -, a prostituição emerge como um rico feixe de 
relações sociais, políticas, econômicas, laborais, familiares e sexuais, que estimula a sua construção como objeto antropológico. No caso do artigo de Fonseca, trata-se de pensar essas pessoas e famílias vinculadas à prostituição a partir da morte do gigolô.

Para Menezes (2004, p. 25), certamente em estreito diálogo como Elias (1989), a partir da segunda metade do século XX nas ciências sociais “[...] a morte se tornou um campo privilegiado de observação e análise da fragilização dos vínculos sociais, da crescente institucionalização e rotinização dos cuidados aos doentes e do processo de ocultamento e exclusão social dos que estão morrendo". Contudo, apesar das análises macrossociais e macro-históricas, este artigo retoma questões e posições colocadas por Claudia Fonseca na sua análise situada. A morte do gigolô gaúcho é analisada como um importante evento público para uma microcomunidade, desde a possibilidade de restituição de vínculos familiares e afetivos, e desde os enlaçamentos de confiança e carinho que produziram as despedidas e funerais do gigolô.

No caso da morte da Carmelo, veremos mais a forma de um combate perpétuo entre processos de docilização e indocilização dos corpos, entre saberes régios e dessujeitados - menores, diria Foucault (2008) citando Deleuze -, entre máquinas de guerra e dispositivos de poder. Interessa a morte, e nisso me reencontro com Claudia, como o último momento desse "combate perpétuo", no qual os tecidos de afetos se reencontram (ou não) para performar, com ampla força emocional, as condições das despedidas, dos enterros e das memórias. Esse processo da morte implica algo como uma demonstração agônica e agonística da trajetória, das decisões e vínculos, da capacidade relacional de um determinado corpo em produzir luto, alegria, regozijo e solidariedade. A morte é então a disputa última (em vida) pela perspectiva. Do familiarismo e a recomposição afetiva pública da morte do gigolô gaúcho à tentação pela pena civilizatória, pela "solidão" da "patroa" transfronteiriça... ao combate perpétuo da (des)sujeição.

Nesse marco, encontramos os processos de precarização como locus performativo no qual fronteira e emoções se encontram e atualizam. Entre a pena, 0 desamparo, o medo, a periculosidade e o intenso desejo de desbravar o mundo, e como forma de fugir das armadilhas mais humanistas inscritas nessa gramática emocional do mito-conceito da fronteira, penso que resultam importantes as propostas de Judith Butler (2010) sobre precariedade. Se, seguindo a autora, 
a precariedade e a codependência são condições ontológicas da vida, e a precaridade seria a produção política, diferenciada e distribuída geopoliticamente: como, então, se produz a precari(e)dade como efeito da fronteira? Como corpos que habitam territórios simbólicos e geopolíticos intersticiais ou marginais habitam essa precari(e)dade? Como se atualizam vínculos de codependência em trajetórias de rupturas biográficas e de exploração econômica? Como se narram - para frente ou para atrás - as formas de uma "vida precária", o estatuto social de uma pessoa? Como é que a precari(e)dade opera como um dispositivo disciplinar, docilizador ou administrador de vidas, populações e territórios?

Por outro lado, como pensar a precariedade ou o "abandono" do qual Carmelo irá nos falar, não apenas desde a sua produção política e econômica, mas desde a gestão cotidiana da vida, do mundo e das relações feitas por pessoas de "malas vidas", em fronteiras e periferias? Dito de outra forma: como é que determinadas precariedades atualizam e contestam os processos de precarização?

\section{Un día de hospital: abandono, precariedade e periferização}

Carmelo meio deitada meio sentada, naquela posição em que podia respirar melhor e segurar a dor. Eu na cadeira de plástico à sua frente, na habitação compartilhada no precário hospital público de Leticia, Colômbia. Ela se lembra do médico Silva, um bom médico, amigo, como buscando em um diretório íntimo de relações os caminhos de "colaborações" e afetos para fazer disso tudo algo um pouco menos terrível. O médico Silva foi aquele que muitos anos atrás "costurou a [amiga] brasileira" da Carmelo, depois que a Marta, sua companheira da época, a esfaqueara possuída pelos ciúmes. (Diário de campo, 27 e 28 de setembro de 2015).

"Carmelo está muito ruim", escrevi na noite do dia 27 de setembro de 2015 na caderneta que cada vez tinha menos vontade de preencher. Vinha piorando desde mais ou menos um mês. Quando cheguei a Tabatinga em agosto daquele ano ela já estava com problemas para respirar, ocasionais, mas fortes. Não conseguia fazer todas as tarefas que costumava e que precisava para manter a casa girando. As mulheres da casa, do negócio, tendiam a não acreditar, a caçoar 
dela. Carmelo não se deixava cuidar, continuava bufando e controlando tudo. Não confiava em médicos e nem em instituições.

$\mathrm{O}$ ano de 2015 foi difícil para a saúde, para os negócios e para o amor. As perturbações físico-morais (Duarte, 1994, 1998) foram também econômico-afetivas. ${ }^{8}$ Especialmente a sua relação com Clara, sua última mulher, 40 anos mais jovem, se tornava um espaço de morte: as idas e voltas, as dores, as brigas e violências, os "malos pagos" (gastos econômicos - excessivos - de Carmelo que, na perspectiva de gênero em jogo, deveriam ser retribuídos no plano amoroso e sexual). Quando nos encontramos em agosto de 2015, ainda na ressaca da tormenta com a Clara, Carmelo tinha uma nova "namorada" chamada Bia, branca, alta, 30 anos mais jovem, trabalhadora muito requisitada do negócio que, no passar das semanas, foi se mostrando menos como uma alegria e um apoio, e mais como uma nova decepção e uma nova razão de "desahucio" [desengano] para Carmelo. O desengano amoroso - econômico e moral - foi sempre devastador para Carmelo; uma pessoa, uma produção de gênero (masculina), que tinha no "corazoncito", "en la orejita con quien pasar las noches", uma base fundamental para "mantener el carriel levantado".

Além disso, os comércios estavam meio parados, o dinheiro circulava menos - devido talvez ao maior controle ao narcotráfico -, a precária casa da Carmelo estava em piores condições, alguns amigos e amigas estavam indo embora da fronteira de forma bastante melancólica... e ela teve uma "culebrilla" ("cobrão", "cobreiro": herpes-zóster) no início do ano.

No dia 22, quarta-feira, estivemos no pronto-socorro pela primeira vez. Passeávamos por Leticia numa das suas duas motinhos quando ela piorou. Teve de sentar na calçada com muita dor no tórax e com muita dificuldade para respirar. Fiz uma pequena massagem, assumi a direção da moto e fomos para o hospital de Leticia.

Carmelo pediu-me para mediar a comunicação. Impressionou-me ver o desencontro gramatical operando entre ela e esse mundo todo das classes,

8 Sigo aqui uma produção antropológica sobre economias sexuais (articulações íntimas entre sexualidade, gênero, afetos, intimidade e dinheiro), com vertentes internas que não vêm ao caso ressaltar: Zelizer (2005); Cabezas (2009); Piscitelli (2016); Olivar (2017).

9 O carriel - bolsa de couro atravessada lateralmente -, forte símbolo biográfico-cultural, materialização da cultura paisa colombiana, dos negócios, da masculinidade... da alegria, da energia, do amor. 
das geopolíticas e dos saberes que se materializava no hospital e seus técnicos (como outras vezes vi acompanhando prostitutas nas suas relações com 0 Estado). Carmelo perdia a capacidade de explicar, de expressar a dor e o mal-estar. Essa pessoa colona, pioneira, que dificilmente encontrava limite nos seus passeios de moto, que falava alto e se movia segura na rua e no prostíbulo, na porta do presídio cobrando dívidas de algum agente penitenciário cliente da casa... essa pessoa recuava, silenciava, pedia mediação, olhava para baixo.

O Doutor Herrera, médico do hospital de Leticia, depois de menos de cinco minutos de consulta, disse que era uma pequena infecção na garganta, ordenou medicamentos para dois dias, consulta externa no dia seguinte e alguns exames básicos. Ela, teimosa e desconfiada, não esperou até o dia seguinte. Entrou na área de consulta externa, se informou qual era o consultório de um médico amigo dela ("meu médico") e esperou até ele chamar. Dessa vez ela entrou sozinha para falar com ele, a relação dispensava o mediador. O "meu médico", que estava sendo candidato a deputado estadual do Amazonas, disse que seria um "refluxo".

Refluxo. Essa palavra me bateu com força. A tristeza que eu (con)tinha de repente ganhou ressonância. Essa palavra conectou mundos e planos nesse universo poderoso e frágil da prostituição e das margens: "refluxo" e a consequente perda de voz foi o primeiro sintoma do câncer que levou à morte da Gabriela Leite, minha amiga, liderança histórica das prostitutas no Brasil. "Meu médico" ordenou medicamentos para um mês e uma radiografia de tórax urgente que só poderia ser autorizada na seguinte semana.

No sábado acordou muito pior, o bar com pouquíssimos clientes, as mulheres bastante preocupadas e a "namorada" ausente. Elas me pediram para falar com Carmelo, para convencê-la. Impossível, como sempre. A tristeza tinha também tomado conta, e era difícil tirar esse peso de cima. Seu quarto de tábuas, zinco, plásticos e papelões parecia ser o último refúgio válido desse mundo, mas agora nos parecia prejudicial. A televisão ligada em alguma série colombiana de narcotraficantes e o celular sempre na mão. Consegui que me prometesse que amanhã de manhã, domingo, iríamos para o pronto-socorro. Não queria. Talvez ela soubesse que o tempo ali seria longo e definitivo... talvez soubesse, como deve saber quem já passou por prisões e hospitais, quem fugiu eternamente dos registros e das leis..., talvez soubesse do processo violento de registro, indagação, sujeição e morte que aconteceria no hospital. "No, Miguelito, no", dizia apenas fazendo bico e baixando a cabeça. 
No domingo 27 de setembro, entramos no hospital de Leticia, Colômbia, pela porta do pronto-socorro, angustiados. Foi imediatamente colocada sob observação com oxigênio e soro, foram feitos exames e radiografias que nos diriam em curto tempo uma previsão diagnóstica. Porém, o amável e certeiro médico que a recebeu foi substituído ao meio-dia pelo mesmo Doutor Herrera, algo como um médico-coveiro, um coletor de almas desenganadas que continuou negligenciando a atenção a Carmelo. Sem informação foram passando as horas. Nessa tarde e noite eu fui o único acompanhante da Carmelo, além de ser sua extensão, numa tecnologia que me conectava com o celular e a moto, para levar e trazer coisas, conversar com as mulheres, encaminhar instruções, fazer compras, voltar ao hospital e mediar com a instituição-saber-Estado.

Às dez horas da noite, decidimos passar por cima do fluxograma institucional e conseguimos que outro médico olhasse as "placas" e nos desse alguma informação. O resultado foi uma internação urgente por "derrame pleural", e a entrada em cena de uma médica, com camiseta de super-herói, que assumiria o caso da Carmelo até o último dia. Eles, finalmente, fizeram uma anamnese completa, quase um interrogatório sobre "estilo" e condições de vida, sobre hábitos, sobre o trabalho dela ("tengo un bar"), sobre consumo de cigarro e álcool. Esse repertório se repetiu várias vezes durante esses dias e sempre houve um pequeno drama ao redor dos 20 cigarros que fumou diariamente durante 20 anos da vida.

Perto da meia-noite, Carmelo, cansada, conectada ao oxigênio e ao soro, perguntou por que não começava a melhorar. A doutora, com sua benevolência e sua camiseta, com seu saber e sua juventude, disse: "Señora, no espere que un día de hospital la cure de 40 años de mala vida." Então ela foi definitivamente internada e, assim, começou a ser incorporada nos termos do saber/poder, da lei, da norma e do mercado da saúde colombiano. Sua vida pregressa seria, a partir de então, uma "mala vida". Melhor, a hipótese da "mala vida", transformando a diferença e a fuga em precariedade, a coragem e o destemor em melancolia e pena, entraria como dispositivo de disciplinamento retroativo para disputar a narrativa que, a partir daí, iria lutar contra a morte e contar essa vida que desfalecia. Adoecida e institucionalizada, a pessoa da Carmelo começava uma nova fase de construção, a partir do desamparo e da acusação. Carmelo guardou aquele silêncio de desacordo e de raiva que eu já conhecia e que disputava espaço com o agradecimento que sentia pela doutora. 
Na manhã seguinte drenaram do costado esquerdo quase $900 \mathrm{~mL}$ de "aguasangre". Nesse segundo dia as mulheres da casa foram cuidar de Carmelo, deram banho, levaram alimentos. Carmelo melhorou significativamente, nós ganhamos esperança, a médica se tornava, de fato, uma heroína. A esperança, contudo, era fátua, pois a "aguasangre" era apenas o efeito de algo que desconhecíamos: um tumor ou uma infecção. Segundo nos foi explicado, o primeiro a ser feito, porque era mais fácil, era descartar a infecção.

E sobrou o tumor. A doutora ordenou então duas imagens urgentes e a transferência, também imediata, da Carmelo para Bogotá. O tema das imagens e da urgência é importante e revela não uma verdade oculta do organismo da Carmelo, mas uma forma através da qual sujeitos em posições sociais de pobreza econômica, adoecimento e múltiplas marginalidades são administrados e diminuídos, precarizados, pelo sistema de saúde do país.

Para entender o que as imagens revelaram é preciso um desvio explicativo.

Na Colômbia, a partir da Lei 100 de 1993, que regula o Sistema General de Seguridad Social en Salud, se estabeleceu que a saúde pública, em todos seus âmbitos e níveis, seria administrada por entidades privadas, inclusive a rede pública de hospitais e centros de saúde, que deveriam se tornar Empresas Sociales del Estado, muitas vezes com capitais mistos e, sempre, tendo que concorrer entre si e ganhar autossustentabilidade financeira. Há fundamentalmente três regimes nessa organização da intermediação privada: o regime contributivo, o regime subsidiado e o regime vinculado. Cada regime é administrado por empresas às quais as pessoas devem-se filiar. O primeiro se ocupa da saúde dos trabalhadores formais e acima da linha de pobreza, que devem contribuir economicamente. $\mathrm{O}$ regime subsidiado cobre as pessoas mais pobres, desempregadas ou com ganhos muito baixos e irregulares, como a Carmelo: indígenas, camponeses, etc. Por fim, está o regime vinculado, que é uma espécie de pronto-socorro para as pessoas em condição de pobreza extrema e que não se encontram filiadas a empresas dos outros regimes. ${ }^{10}$

A empresa à qual Carmelo era filiada era, na época, a maior administradora do regime subsidiado em número de filiados, mas na mesma época começou seu processo de liquidação, em razão de escândalos de corrupção, de péssima

10 Sobre o sistema de saúde colombiano, ver, entre outros, Guerrero et al. (2011), e Levino e Carvalho (2011) para uma análise comparativa com o Peru e o Brasil. 
administração e de dívidas impagáveis às empresas de prestação de serviços (hospitais, centros de diagnóstico e recuperação, etc.). O hospital de Leticia era um desses credores que começava a negligenciar serviços.

Por essas razões, quando foram solicitadas as imagens diagnósticas, as boas vontades, rezas e esperanças entraram na fossa séptica do sistema, da margem e do azar, enquanto toda uma gramática emocional da dor, da tristeza, da "pobreza" e da "solidão" ganhava força. Em Leticia, capital do estado de Amazonas (Colômbia) e cidade de referência da Amazônia colombiana, não havia estrutura, especialistas (oncologistas) e nem recursos para cuidar da Carmelo caso o diagnóstico, como começava a ficar evidente, fosse câncer. A fronteira emergia precarizada e periferizada; uma melancolia, um fim do mundo.

Depois de um mês e meio hospitalizada em Leticia, sem diagnóstico e sem oxigênio nem soro permanentes, sem mobilidade e sem dinheiro, sem parentes consanguíneos e nem namorada, Carmelo foi finalmente transferida a Bogotá.

\section{Mala vida: pena, moralidade e operações de sujeição}

A palavra sem do parágrafo anterior marca a emergência da "solidão" e da pena no reforço dos sentimentos de falta e desamparo. No processo de adoecimento da Carmelo os esforços para proteger sua vida implicaram esforços de registros, normalização e sujeição. O que estava em jogo era a memória de toda uma vida, a memória futura. Mais, o que estava em jogo era a produção última da própria pessoa; o ponto de vista. Ou seja, o que estava em jogo era, justamente, o jogo de afetos e emoções associados a uma vida intensamente relacionada com a fronteira; a tensão entre a normalização institucional a partir de âmbitos e técnicas específicas, e a capacidade de eficácia das invenções biográficas da Carmelo e sua rede atravessadas pelas fronteiras.

Qual era a mala vida à qual a doutora se referia, da qual não sabia nada em absoluto, mas que lhe servia para iluminar linhas explicativas da doença e para contrapor a sua compaixão, a sua benevolência salvadora (super-heroica) e a possível eficácia institucional do hospital? Quem é essa pessoa que está hospitalizada? De qual solidão, de quais formas de coragem, de melancolia, de tesão e de amores estamos falando? Proponho ver essa tentativa de sujeição 
rapidamente em cinco campos de confronto: o gênero-e-sexualidade, a fronteira, o parentesco, a vida noturna e o dinheiro-amor.

\section{Gênero-e-sexualidade, documentos, biologias}

Durante décadas, Carmen construiu para si um espaço largo para vivenciar e produzir o gênero, no qual formas de masculinidades e de feminilidades se autodiferenciavam, se cruzavam, contrapunham e alimentavam constantemente. Não havia agrado com algo que poderíamos pensar em termos de simultaneidade de gênero ou de apagamentos identitários ou de androginia. "No, Sarita - dizia para uma das mulheres - o Carmelo, o Carmen, pero eso de Doña Carmelo, no!!!" E ria largamente. Carmen ou Carmelo, mas não as duas referências de forma simultânea e, muito menos, alguma terceira. Como se fosse uma seguidora da Gayle Rubin (1986) dos anos 1970, Carmen afirmava algo como uma realidade natural que para ela não tinha qualquer espaço de discussão (ser uma mulher) ao tempo que Carmelo indicava a realidade lésbica-masculina que era sua particular experiência e que era simultaneamente indiscutível.

Uma Carmen lésbica, de roupas, cabelos, gestos, gostos, desenganos e práticas econômicas definidas por ela e pelo mundo ao redor como "masculinas", que foi várias vezes marido, que exerceu a paternidade em enteados e que se tornava avô. Era a Carmelo com quem eu estabelecia conversas "de hombres" no bar, prenhes de sentimentos de solidariedade de gênero. Ou a Carmen que me pensava como um filho "de las entrañas", que era incapaz de se imaginar "machorra" (uma espécie de perda completa da "feminidad" que ela via em outras mulheres lésbicas), e que era a "madrinha" do André.

No hospital, Carmelo foi transformado de vez em mulher, em Doña Carmen Rosa, com seu nome completo escrito sobre a cama, com data e lugar de nascimento, com o pijama feminino de mariposas que o hospital em Bogotá fornecera (e que Carmelo odiou), com seu histórico na saúde da mulher. Minha mãe? Minha tia? Uma mulher envelhecida.

\section{A transformação da fronteira em fim do mundo}

Na história da Carmelo a fronteira não é apenas, e é profundamente, esse lugar de moradia chamado fronteira. Carmelo cresceu na cidade de Villavicencio 
nos anos 1960, uma cidade que foi base para a expansão da fronteira agrícola colombiana a partir de Bogotá. Durante os anos 1970, viveu na cidade de Santa Marta, no extremo norte da Colômbia e perto da fronteira com a Venezuela, "contrabandeando" produtos deste país para vender na cidade - marcada pelo comércio internacional de maconha. No ano 1981 atravessou de norte a sul o país correndo atrás do murmúrio saboroso da bonança da cocaína, que tinha como um dos seus paraísos a cidade de Leticia, Amazonas, fronteira com o Brasil e com o Peru.

Fronteiras, margens, periferias, limites, zonas foram então muito mais que acidentes geopolíticos na experiência da Carmelo; constituíram em muitos sentidos o seu centro existencial, sua gramática. Carmelo narrava essas aventuras com enorme felicidade, com a melancolia das despedidas, com a satisfação da "vida no trecho" (Guedes, 2013) e da boa memória para contar detalhes. Porém, a institucionalização precária do adoecimento tinha o efeito de transformar a fronteira numa lonjura, num fim de mundo. Além disso, o limite internacional se levantou na sua eficácia emocional, corporificada. Apesar de ela morar e trabalhar em território brasileiro, e apesar da potencial melhor infraestrutura de saúde, o Brasil virtualmente desapareceu do mapa da cura dadas as fortes emoções hierarquistas, xenófobas e racistas que orientam a prática do SUS nessa fronteira. ${ }^{11}$ Enquanto isso, Colômbia, e não apenas Leticia, se fazia hegemônica no desastre. Ali, aquele quarto de hospital, aqueles médicos que uma tarde se negaram a conversar conosco porque tinham pressa para assistir ao jogo de Colômbia contra Uruguai pelas eliminatórias... ali era não a fronteira, mas o fim do mundo que testava todas as nossas capacidades ao máximo, todos os nossos recursos e vínculos: amizades, sedução, conhecimentos jurídicos, oração, remédios indígenas, saldo no celular, modulações gramaticais... tudo. Fazer uma fronteira, e fazer que a fronteira se sinta uma periferia, é produzir performativamente cenas e afetos de ameaça e desamparo.

11 Carmelo nunca nem cogitou buscar atendimento em Tabatinga, era algo impensável para ela, e certamente não teria sido atendida. Em Tabatinga a universalidade do SUS tem fortes limites nacionais e é administrada pelos afetos nacionalistas dos profissionais da saúde e militares do Hospital da Guarnição. Fora os muitos exemplos que poderia oferecer sobre isso, sugiro ver o trabalho da antropóloga Ana Campos (2012), habitante dessa fronteira, que mostra um pouco dessa dramática configuração a partir da sua etnografia de partos de mulheres peruanas em Benjamin Constant (AM). 
Por fim, no dia 8 de novembro pousou em Leticia o pequeno jato-ambulância que viria a "sacarla de aqui". Uma cena épica, quase uma resgate na/da fronteira. A imagem marca com força a produção espetacular da situação periférica: os homens médicos brancos, bogotanos, com nome corporativo em inglês nos seus macacões, munidos de uma tecnologia inexistente em Leticia, impressionados com o absurdo da demora, da falta de oxigênio. Carmelo se despede com lágrimas nos olhos, com alegria e tristeza e com a incerteza sobre quais serão as últimas imagens que guardará de Leticia, sua fronteira, seu centro do mundo dos últimos 35 anos...

\section{Parentesco, aliança e a suspeita da solidão}

Como outras mulheres que conheci em campo, Carmelo chegou a Leticia sem parentes consanguíneos e sem redes de amizade. Kati, uma amiga e contemporânea dela, me disse certa vez: "Cuando uno se va solo, le toca hacerse su propia familia en el lugar al que llega." Quando Carmelo e La Rubia, sua segunda mulher, saíram de Villavicencio, o avô ("papito") havia morrido, e, antes, a avó ("mamita"), familiares com quem Carmelo cresceu e a quem ela amava mais que ninguém. Seus pais e seus irmãos estavam vivos, presentes e moravam na mesma cidade. Contudo, Carmelo foi embora, quebrando para sempre todos seus vínculos consanguíneos. Essa ruptura radical e absoluta do parentesco filial e genealógico pela aliança homossexual - um precioso tema butleriano (Butler, 2004) - esteve sempre banhada de silêncios nas nossas conversas; apenas uma vez, uma única vez, ela mencionou uma lembrança que pode ajudar a entender o marco afetivo das relações e decisões. Carmelo lembrou que ainda jovem, começando a namorar mulheres (mas esse é um complemento meu, não dela), seus pais a internaram numa clínica psiquiátrica durante algum tempo. Nesse marco, somente seu avô aparecia nas narrativas como franco cúmplice.

Em 1981 chegou a Leticia com La Rubia e começou sua produção de dinheiros, afetos e parentes. A primeira foi "Mamá Amparo", uma mulher 15 ou 20 anos mais velha, comerciante e "rezadora", que a adotou e a protegeu até o dia da sua morte. Eu - "como un hijo de mis entrañas" -, 30 anos depois, pude ter sido o último. No meio da linha houve mais cinco mulheres (em termos de conjugalidade), "hijos" e "hijas", "como hermanos", "ahijados", e dezenas de amores, amantes, amigos e amigas principalmente no lado colombiano da tríplice 
fronteira, nas entranhas do Estado, nos comércios legais e ilegais, na polícia e na prisão.

No adoecimento, a "falta de familiares" virou uma questão para o corpo médico e para alguns amigos. Para algumas mulheres do negócio e para outras amigas, a falta de uma "compañera", de uma "buena mujer" ao seu lado, era um motivo especial de preocupação, crítica e angústia. Na lógica que atravessa toda essa narrativa, a falta de um amor bom, de uma mulher que cuidasse dela, estava diretamente associada ora com a doença, ora com a precarização da vida durante a doença. Sentimentos de pena referentes à solidão foram tomando conta da narrativa, e flutuava no ar a questão de se ela gostaria de localizar ou não os familiares de sangue.

Afinal, quem resolveu o embaraço da transferência para Bogotá foi a sua ex-enteada Andrea. A mãe de Andrea, penúltima companheira estável da Carmelo, estava reclusa num presídio na Colômbia, condenada por "trata de personas" entre outras acusações. Nos dois últimos anos, Andrea, motivada pelo amor à sua mãe e mobilizando amizades e outros afetos, percorrera os labirintos judiciais de papéis, prédios e pessoas buscando reverter ou reduzir a pena. Esse conhecimento fez possível articular nos caminhos e termos certos a Acción de Tutela (espécie de mandado de segurança) que garantira, finalmente, a transferência para Bogotá. Além disso, Andrea viajou a Bogotá como acompanhante de Carmelo.

Mas apesar de tudo isso, a narrativa da solidão foi tomando conta da perspectiva. No dia da viagem a Bogotá estávamos Andrea e eu, ninguém mais. Ninguém mais, e por tardes inteiras estive somente eu no hospital. Mas estava $o$ celular, aquele dispositivo precioso de criação de mundos e de controle vital... A mãe da Andrea se comunicava desde o presídio com frequência, igual que outras dezenas de mulheres desde diversos lugares do país. Mas as mulheres do seu negócio deixaram de ir, se transformaram em inimigas, em pura dor: "Esas mujeres me abandonaron."

\section{A vida noturna, "el perreo"; segredos e formas de mala vida}

Desde o final da década de 1970 até mais ou menos o ano 1989, Leticia viveu sua época de ouro, conhecida como "la bonanza" (do tráfico de cocaína). E foi esse o contexto que Carmelo desejou e do qual participou intensamente como 
agente e mediadora local. Depois vieram os bares de música e bebidas e depois o comércio sexual organizado. Os anos de farra e narcotráfico, de motos e mulheres, de uísque e "Antártica", o cigarro do malandro, as noitadas, as sacolas de dinheiro, as jornadas de administração do puteiro, a homossexualidade fértil e promiscua ("el perreo"), sua facilidade para amar e se apaixonar, e até a posterior simplicidade estrutural da sua casa/negócio... tudo se resumiu a "40 años de mala vida" que deveriam ser "curados" e que deveriam ser conectados com a doença. Mesmo que o mortal e raríssimo câncer de timo que lhe foi diagnosticado em Bogotá não tivesse nada ver com isso. Mesmo que ela bebesse pouco, que há anos tivesse abandonado o cigarro e que sua experiência de uso de outras drogas fosse limitadíssima.

Insistentemente lhe perguntavam não apenas sobre o cigarro, mas sobre as caraterísticas da moradia, sobre o tipo de negócio, sobre a alimentação. Fariam uma investigação clínica? Não. Apenas produziam performativamente uma "mala vida", um gesto no rosto que conectava, na obviedade flutuante daquilo sobre o qual o especialista omite explicações, a doença com a "mala vida"... Precariedade sobre a margem sobre a fronteira. Parecia ser importante manter presente na reclusão hospitalar as imagens, sentimentos e sensações da "mala vida", da pobreza e precariedade. Para dialogar com Duarte $(1994,1998)$, uma perturbação física (talvez físico-afetiva?) é então produzida no âmbito da atenção médica não como uma disfunção biológica, mas como um desvio físico-moral (impossível não lembrar de Sontag (1989) e sua crítica clássica às metáforas sobre o câncer e sobre a Aids).

\section{Sua economia/afetividade foi transformada em pobreza e em "burrice"}

O adoecimento hospitalizado, como já mostrei, esteve desde o início conectado com uma crise econômico-afetiva que ia além das paredes da casa-negócio. O mal-estar físico foi associado ou colocado no plano das especulações afetivas e nas avaliações morais do uso do dinheiro e do autocuidado. A afirmação constante, que eu ouvia e repetia, era que Carmelo não tinha nada. Mas acontece que Carmelo não era uma acumuladora e nem ambicionava uma vida de classe média. Carmelo produziu uma vida de economias altamente circulantes e colaborativas. Antes do adoecimento, jamais faltou dinheiro porque não podia faltar, porque no estilo de masculinidade que ela performava era o dinheiro 
o motor do sexo e dos afetos, "del corazón y del carriel”. Mas também não devia ficar, porque o dinheiro acumulado traz desgraça, porque o dinheiro em movimento (a caça do dinheiro, o risco de perdê-lo) era um campo de jogo, de tesão e de intensidade privilegiado; um especial objeto de troca em cuja circulação se produziam os negócios, a "colaboração", a "ajuda", ${ }^{12}$ o pagamento, o sexo, os afetos - vida, relação -, e o gênero. Ganhar dinheiro e dá-lo, fazê-lo circular, calcular as dádivas e saber o retorno justo, estavam na base da produção da masculinidade e, assim, da vida social, sexual e afetiva de Carmelo. Aí vem o "mal pago", que coincide com a "culebrilla" e com o início dos sintomas do câncer: Clara, a última ex, teria roubado da Carmelo uma poupança que guardava, e teria gastado o dinheiro montando um apartamento conjugal com o pai do seu filho (que na nossa perspectiva era "hijo" de Carmelo) em outra cidade.

$\mathrm{O}$ adoecimento, então, liberou as pessoas para exercerem seu poder de crítica, para manifestar-se (é verdade, contra uma figura de poder). "Carmelo es muy boba Miguelito!!!", “Carmelo no tiene como arreglar el techo, pero gastó 8 millones de pesos para visitar a Clara", "Usted cree que Carmelo le hizo caso de quedarse en la casa como usted le dijo??". Algumas das mulheres buscavam em mim um mediador com a teimosia da Carmelo, ou buscavam revelar-me uma verdade que eu desconhecia. O fato é que um dos primeiros efeitos do adoecimento foi a transformação verbalizada da vida econômico-afetiva da Carmelo num objeto de discussão e de avaliação, de fofocas e críticas. Isso, claro, se agudizou no hospital, em que tudo foi traduzido como "pobreza" (na classificação estatal mais baixa: "estrato uno"), "solidão" e "mala vida".

Para completar, essas economias-afetos foram rapidamente capitalizadas por algumas das mulheres que trabalhavam na casa quando Carmelo adoeceu. Em menos de um mês Carmelo perdeu o controle do negócio, perdeu os eletrodomésticos velhos e deixou de receber dinheiro, enquanto a dona do local em aliança com pelo menos uma das mulheres e seu marido tomavam conta de tudo. Pouco sei das motivações concretas das mulheres para tamanha espoliação, posso apenas imaginar que em economias de precariedade e extração

12 Sobre o lugar da "ajuda" nos chamados mercados sexuais existe uma produção abundante (Piscitelli, 2013, 2016). Contudo, em boa parte dessa produção, o dinheiro, suas formas materiais e relacionais, sua circulação e sua imbricação coprodutiva da sexualidade e do gênero, continua pouco estudado. 
marcadas pelo intenso desentranhamento (no caso das prostitutas-na-fronteira) e por destemores imaginados como individuais, há pouco espaço para algo como a compaixão.

Carmelo morria duplamente empobrecida. "Esas mujeres me abandonaron", repetia uma e outra vez. Para ela "el deshaucio" e a "traição" no plano amoroso-econômico, bem como o "abandono" das mulheres constituíam a verdadeira razão de tristeza e a forma da solidão. Como veremos a seguir, havia paz em suas decisões familiares, em sua trajetória e estilo de vida, em sua construção econômica precária: a tormenta era mais próxima e mais imediata.

\section{Y el cadáver? Aliança e teimosia: cuidado e territorialização desejante}

Como temos visto até agora, há na fronteira uma excitação mítica e produtiva ao redor e a partir de ideias sobre desejo, sobre aventura, força, intensidade, descobrimento, expansão (Martins, 1997; Serje, 2005; Turner, 1993). É ao que nos remetem as figuras dos heróis e dos pioneiros. Bem, com risco de cair na armadilha que conecta a exaltação colonizadora e a mitologia do self-made man,13 devemos entender que há na gramática emocional e normativa da fronteira, $\mathrm{e}$ portanto na experiência física e territorial da Carmelo, um rastro desse sistema de emoções, afetos, sentimentos e sensações. A coragem, o destemor, a excitação pela sobrevivência, o desejo pela fronteira e pelas alianças não genealógicas, a persistência da capacidade de se desmarcar da gramática maioritária de centros e Estados.

A disputa mítica, então, se manifesta de forma mais clara entre a pena e o abandono, de um lado, e o desejo pela "bonanza", pela margem, pelos rearranjos das afinidades, pela aventura, a teimosia, a persistência e a alegria, do outro. Não se trata de uma chave dialética de oposições, mas da conjugação simultânea de tensões e conflitos, e desse conflito perpétuo como condição de possibilidade do mito-conceito e do seu risco na prática (Sahlins, 1985).

13 Ver a certeira crítica de José de Souza Martins (1997) a essa celebração. 
Se metáforas de genealogia e filiação, como o Estado-nação, a lei, a hereditariedade e o povoamento são eixos fundamentais na leitura mais estabilizada dos processos de fronteirização (Grimson, 2003), a torção que tentamos aqui diz respeito à figura analítica da sexualidade e da afinidade, do desejo e da sedução, da carnalidade e da comensalidade. Por isso não é a solidão (Elias, 1989) o eixo estruturante dessa gramática, mas a voracidade benevolente com que a solidão, afiliada ou não à compaixão, tenta se impor como perspectiva de fronteirização. O eixo é o combate. Por outro lado, antropologicamente devemos entender que Carmelo não foi propriamente uma moribunda até que morreu: ela não estava morrendo, ela estava doente, iria se curar e iria voltar ao jogo. Ou quiçá se tornou moribunda uns dias antes da morte, quando a decomposição do corpo foi sendo evidente sem quase ninguém saber que ela se tornara moribunda.

A teimosia emerge, assim, como um vetor de vinculação, como uma linha afetiva através da qual se faz possível o mundo em movimentos de ruptura e fuga (mas não só). O que faço nesta última seção, então, é abraçar o conflito remarcando as possibilidades de fuga ou de desvio (analítico) a partir da paisagem de penas e sujeições desenhada anteriormente. Lembremos que, talvez na linha das explicações de Elias (1989) sobre a morte, a narrativa hegemônica da pena remarcou paulatinamente o ponto de vista da solidão, da ausência de familiares e de "una buena mujer". Mas que solidão é essa?

Revisando o diário de campo, encontro no quarto da Carmelo uma constelação de amigos e amigas, de afetos e afinidades recompondo permanentemente a coreografia dos afetos e da "solidão". Médicos, uma fisioterapeuta, filhos de médicos, políticos, comerciantes, prostitutas e ex-prostitutas, gays e índias que trabalharam na casa nas funções logísticas, guardas penitenciárias, ex-presidiários, policiais, amigas migrantes, o afilhado, a "namorada", a dona do local e a Andrea... Além da infinidade de ligações via celular e da queixa pública contra a negligência estatal-empresarial em enviar Carmelo a Bogotá feita na rádio local. Carmelo era uma figura pública em Leticia, ainda que de um público marginalizado: nos meses posteriores à morte, muitas foram as palavras de consolo, as lembranças e carinhos, as flores e velas que transitavam por Leticia com o nome de Carmelo.

E a solidão bogotana? A figura central na narrativa bogotana é, além da Andrea, a Doris, outra ex-companheira. Além delas estive eu, esteve também a irmã caçula da Andrea ("mi hija"), e a Mamá Amparo, que viajou para fazer uns 
exames de rotina. Todos nós, como uma copresença que materializa sua eficácia a partir da ação fractal de múltiplos corpos, atos e afetos (Bumachar, 2016) para produzir uma vida, ou um fim-da-vida, mais digno. Uma vida digna de ser chorada, digna de luto (Butler, 2010), digna de uma memória devedora da vida (e não apenas da doença e do hospital). Em Bogotá Carmelo me pediu, com um sorriso de cumplicidade, que lhe desse de presente um pijama "de hombre". Na beira da morte, restaurava-se no gênero, na narrativa pública da sua masculinidade, na produção do corpo através da amizade e da única roupa possível.

Trata-se então de uma solidão muito específica: aquela que povoa a imaginação maioritária da nação e da família consanguínea ou conjugal. A solidão produzida pelo "resgate" e pelo próprio dispositivo de fronteirização. A solidão enquanto afeto e efeito de docilização.

Apesar da ostensiva força institucional, Carmelo não parecia entregar-se ao saber régio. Uma noite no hospital de Letícia conversávamos descontraidamente com a doutora que tanto nos ajudou, ela comentava sua percepção sobre a noite, a sexualidade e a juventude da cidade. Como costuma acontecer, uma conversa como aquela cai na "prostituição". Então a doutora perguntou-me se em Leticia havia prostituição. Eu olhei um pouco incrédulo, olhei para Carmelo que se fazia de distraída na tela do seu celular. Um mês de hospitalização, de instituição total, não tinham conseguido fazer chegar nos ouvidos da doutora o verdadeiro ofício da Carmelo? E sua participação antiga no tráfico de drogas? E os períodos na prisão? Depois Carmelo simplesmente ria da cena, mas nada dizia. Também para mim houve amplas parcelas de informação que nunca foram reveladas, muitos aceites de entrevistas que, por razões logísticas ou francas recusas, nunca aconteceram.

E apesar da "solidão", nunca, em nenhum momento, nem por um segundo até o dia da sua morte, ela me pediu para localizar ou informar a sua família consanguínea. Nunca se entregou ao poder médico ou à genealogia, ou permitiu que se construísse uma narrativa vitimista ou compassiva da sua vida. Em Bogotá ela teimou até o último dia com o pijama, com a comida que não gostava, com o banho rápido da enfermeira, com a temperatura da água, com o penico indignante do lado da cama, com a amizade que em alguns casos se transformou em parentesco. Não teimava para se queixar, mas para produzir alianças e mudanças que estivessem mais de acordo com seu desejo ou seu costume. 
Contudo, dizemos que Carmelo morreu sozinha aquela noite na distante Bogotá que nunca lhe pertenceu. Tudo feito para a morte ser banhada de tristeza: a solidão, a ausência de compaixão, o silenciamento (Elias, 1989). Ela foi retirada da sua terra em um gesto épico de fronteirização: retirada em um resgate inútil, tardio, desenganado. Desde alguns dias antes da sua morte, Andrea deixou de frequentá-la. Segundo me disse, teria ido visitar a sua mãe encarcerada em outra cidade próxima. A irmã caçula da Andrea a quem Carmelo chamava de "hija", Mamá Amparo e eu havíamos viajado para as cidades onde residíamos. Somente a ex e amiga Doris manteve a presença esporádica até o final. E Bia, aquela última namorada que não esteve presente no adoecimento, me disse depois que foi a última pessoa a vê-la, como que disputando a memória dos últimos momentos, das despedidas e imagens derradeiras.

E o cadáver? Carmelo jamais falara comigo da morte, e eu não me senti com direito de impor essa verdade. Afinal, falar sobre a morte, diferentemente de como propunha Elias, não é apenas um gesto moderno e compassivo, mas é um ato criativo. O problema dessa não conversa é que eu não sabia se ela havia preparado algo para seu enterro. Na minha última visita a Carmelo em Bogotá, antes de me dirigir ao aeroporto com destino a Guarulhos, deixei um post-it com meu nome e números de telefone. Na noite do dia 17 de dezembro de 2015, quase à meia-noite, uma mensagem da minha mãe me comunicava a morte da Carmelo. O hospital esperava a minha decisão sobre o que fazer com o cadáver. Ouvia conselhos sobre cremação ou sobre enterro em Bogotá e a narrativa da solidão, a tentação de contar a história desde o ponto de vista do final mais triste do mundo, ia ganhando espaço em mim: eu não queria decidir assim, não era justo com ela. O cadáver da Carmelo em Bogotá, esperando uma decisão tomada desde algum recanto no Brasil distante, sem seguro funerário, sem putas fazendo algazarra, sem carro de bombeiros em Leticia transportando uma das suas figuras mais preciosas, sem família mobilizando-se... O que Carmelo iria preferir?

Rapidamente, enquanto conseguia informação sobre valores e procedimentos, consegui localizar a Andrea. Ela tampouco sabia o que fazer, mas iria assumir a tarefa presencialmente. Passaram-se mais dois dias sem comunicação com ela, até que, por fim atendeu a minha ligação e então consegui entender a potência da teimosia e das alianças. Afinal, Carmelo não ficaria sozinha em Bogotá: estava sendo enviada a Leticia, onde seria enterrada. Mamá Amparo, 
anos atrás, havia incluído a Carmelo no seu seguro funerário. Quando da morte, ela se conectou diretamente com Doris, a quem conhecera anos atrás, para resolver o trâmite do envio do corpo a Leticia. Eu não sabia de nada e nada foi falado na internação porque, certamente, eu não precisava saber.

Assim, na mistura entre teimosia-assim-tornada-infinita, tecidos de dinheiros e afetos, redes de parentesco-na-ruptura e na migração, materializava-se pela última vez, e como última cartada do jogo das (in)docilizações, o desejo pela fronteira. A imagem de contraefetuação do mito é preciosa: a anti-heroína da fronteira, mulher "arepera" pai-e-mãe, em alianças femininas laterais volta (morta e para sempre) a seu pedaço de terra na fronteira. A alegria desse movimento perdurava depois dos anos, e aqui encerro essa narrativa, no riso debochado e satisfeito que é a marca constante dos sonhos que pessoas como Bia (a última namorada), Mamá Amparo e eu temos com ela.

\section{Concluindo: sua fronteira, seu centro do mundo}

Argumentei neste artigo em favor de uma compreensão etnográfica da fabricação social da fronteira a partir do evento do adoecimento e morte da Carmelo. Tal motivo me permitiu adentrar em uma possível gramática emocional e afetiva da fronteira na sua conceitualização como mito-conceito performativo. Essa gramática, como é claro, não é atributo de uma ideia universal de fronteira; ela é situada e existe de forma atrelada às práticas de produção/habitação moderna dos territórios de fronteira, e mantém relações diferenciais com as diversas pessoas e agentes, dependendo das suas posições sociais, suas trajetórias, entre outras. Isto é, mostrei neste artigo como a fronteira atravessa de formas diferenciais os corpos e as vidas das pessoas que nela habitam, constituindo-se num intrincado enlaçamento emocional e material cuja condição de possibilidade é a prática dos sujeitos em relação.

Essas gramáticas emocionais, seguindo a bibliografia referida, são relativamente mapeáveis, não como estruturas universais, mas como disposições culturais associadas ao mito-conceito colonial e metropolitano da fronteira. Mostrei como, fazendo um exercício sintético, é possível pensar dois sentidos dessa gramática emocional: afetos e sentimentos, associados ao projeto de exploração da fronteira (coragem, força, destemor, excitação pela aventura, 
pelo descobrimento e pela sobrevivência, sobrevalorização da individualidade - masculina e antropocêntrica), de um lado, e do outro, associados aos projetos civilizatórios em versões diversas (pena, compaixão, benevolência, medo). Essa gramática emocional implica processos sociais e políticos de produção localizada da precariedade, em termos de Butler (2010), o que significa, para o nosso caso, processos de periferização e empobrecimento de lugares, territórios, corpos, vidas, trajetórias. Ou seja, a ativação e atualização prática da coragem ou da pena mobiliza a transformação de determinados sujeitos ou lugares ou vidas em pobres, em "malas vidas", em periferias ou reveses.

Essa estratégia me permitiu navegar pela trajetória da Carmelo, especialmente a partir da reconfiguração narrativa e evocativa (Skoggard; Waterston, 2015) do seu adoecimento e morte, tecendo de forma permanente a fronteira como um objeto biográfico e cuja materialidade passa pelas disposições emocionais próprias e dos regimes de poder do Estado (nesse caso, da saúde). Por esse caminho, tentei mostrar como, na confluência formativa entre fronteira, "mala vida" e adoecimento, emerge um combate perpétuo entre forças de sujeição e energias de dessujeição. Mostrei como o combate pela pessoa operou ativamente em cinco planos importantes para Carmelo: 1) seus estilos e performatividades de gênero; 2) sua relação com os territórios de fronteira; 3) suas relações de parentesco; 4) sua relação com a prostituição, as drogas e a noite; e 5) as formas em que enlaçamentos de dinheiro, sexualidade e amor ganharam centralidade na sua vida.

Como efeito dessa disputa, novamente, a fronteira adquire diversas formas, na multiplicidade emocional e perspectiva que a caracteriza. Ora um fim do mundo, ora um centro existencial, ora uma periferia atrasada, ora um limite intransponível entre países e entre tecnologias, ora uma terra para a eternidade, ora um território de fugas e lateralidades.

Por fim, recuperando o diálogo inicial com o trabalho de Claudia Fonseca (2004), a morte do gigolô, ou da cafetina de fronteira, implica uma atitude mais ou menos explícita de avaliações morais e afetivas da vida vivida. Avaliações das quais o/a antropólogo/a participa. Nelas os afetos, o dinheiro e os vínculos familiares parecem ocupar um lugar muito importante: é moralmente decisivo não morrer sozinho (Elias, 1989). Mas que solidão é essa? No caso estudado por Claudia Fonseca, a reunião familiar e conjugal em torno do gigolô morto mobiliza possibilidades analíticas que dizem respeito, justamente, às fronteiras 
da transgressão como recurso analítico da prostituição. No caso da Carmelo, é também esse conjunto relacional e moral que está em jogo, mas, como vimos, as conexões empíricas e teóricas conduzem para outro lugar: o do valor dos corpos em aliança e das trajetórias de fuga e indeterminação.

Assim, finalmente, mostrei como, na evidência da morte, tal combate adquire uma forma derradeira em que o corpo, as explicações da doença e a vida são objeto de disputa pela perspectiva última. Isto é, a iminência da morte coloca em ação sua própria gramática emocional, que inclui o estímulo a julgamentos morais e avaliações de trajetória, fazendo com que a totalidade da pessoa - e também daquele lugar chamado fronteira - esteja disponível sobre a mesa de disputas.

Perceber isso tem implicações na análise das gramáticas emocionais, pois analisar essas emoções desde os atos performativos relacionais e desde seu caráter de atualização ou contraefetuação gramatical permite compreendê-las como não estáticas. Nem no eixo temporal nem no eixo axiológico. Além disso elas exigem análises intensamente perspectivadas. Essa condição pode ser vista claramente na disputa pela narrativa da vida da Carmelo enquanto a possibilidade da morte ganhava força. A trajetória vinculada ao caráter "heroico" da fronteira, marcada por emoções como a coragem, se transforma biográfica e perspectivamente na solidão dos moribundos. Uma verdade é o "herói" quando desapega ou desbrava, outra é a velha pioneira abandonada; uma é a voracidade vista por quem deseja, outra quando é vista pelo objeto desejado. Nunca essas emoções são apenas elas ou coerentemente elas: o retorno épico do cadáver da Carmelo-pioneira-indivíduo só é possível pela gestão relacional, compartilhada, dessa gramática emocional (do destemor à solidariedade) transformada em circuito afetivo entre ela, Doris, e Mamá Amparo. E este texto. Como vimos, a solidão abre novamente passo (em mim) para a (re)emergência da emoção orgulhosa, teimosa, contrafronteiriça de ver a Carmelo voltando à terra escolhida, sua fronteira, seu centro do mundo.

$\mathrm{Na}$ antropologia que faço não costumo incluir análises ou descrições maiores sobre minha experiência e meus afetos no trabalho de campo. Porém, nesse caso tal lugar se tornou inescapável. O trabalho etnográfico é um trabalho relacional. Em determinadas situações, torna-se uma relação muito cara para as pessoas com que trabalhamos, pois estamos aí (nas suas casas, nas suas vidas) com tempo e atenção concentrados nelas, estamos presentes, dispostos, 
solícitos. Queremos e precisamos ouvir, acompanhar, reconhecer, compreender, fazer parte. Passamos juntos meses, dias-após-dias, festas, adoecimentos, tristezas, crises. Nos tornamos amigos em termos muito particulares: nosso trabalho consiste em ter muito tempo disponível para elas e eles. A configuração do meu trabalho de campo em Tabatinga em 2015 foi absolutamente diferente do planejado. Eu larguei o meu planejamento, no qual trabalhar com Carmelo não era central, e dediquei boa parte das semanas e das horas dos dias a estar com ela e participar do seu cuidado. E não foi apenas ela. Pelo menos outras duas pessoas muito próximas passaram por momentos muito difíceis e demandaram de mim aquilo que eu demandava e oferecia: tempo, presença, ouvido, palavras. Por fim, eu me permiti o desvio, entendi - quiçá lembrando da Haraway (2011) e do diálogo que com ela tece Strathern (1991) - que essa presença e partilha é parte integral do meu trabalho. Então há nesse novo circuito de afetos implicações mútuas. $\mathrm{O}$ circuito de afetos que me conectava com Carmelo, e as emoções que atravessaram esse trabalho de campo, marcam a forma da reconfiguração narrativa deste texto e dão forma ao caráter evocativo dele. Fazemos uma prática científico-acadêmica profundamente emocional; emoções e afetos os mais diversos produzem o conhecimento que produzimos, impactam trabalhos de campo, financiamentos e trajetórias profissionais.

\section{Referências}

ABU-LUGHOD, L.; LUTZ, C. Introduction: emotion, discourse and the politics of everyday life. In: LUTZ, C.; ABU-LUGHOD, L. (ed.). Language and the politics of emotion. Cambridge: Cambridge University Press, 1990. p. 1-23.

ANZALDUA, G. Borderlands/La Frontera: the new mestiza. 4th ed. San Francisco: Aunt Lute Books, 2012.

BUMACHAR, B. Nem dentro, nem fora: a experiência prisional de estrangeiras em São Paulo. 2016. Tese (Doutorado em Antropologia Social) - Instituto de Filosofia e Ciências Humanas, Universidade Estadual de Campinas, Campinas, 2016.

BUTLER, J. Actos performativos y constitución del género: un ensayo sobre fenomenología y teoría feminista. Debate Feminista, v. 18, p. 296-314, 1998.

BUTLER, J. Gender regulations: undoing gender. New York: Routledge, 2004.

BUTLER, J. Marcos de guerra: las vidas lloradas. Barcelona: Paidós, 2010. 
CABEZAS, A. Economies of desire: sex and tourism in Cuba and the Dominican Republic. Philadelphia: Temple University, 2009.

CAMPOS, A. M. Dilemas da maternidade: assistência a grávidas na rede municipal de saúde de Benjamin Constant/AM. 2012. Monografia (Graduação em Antropologia) - Instituto de Natureza e Cultura, Universidade Federal do Amazonas, Benjamin Constant, 2012.

CLARK, C. Misery and company: sympathy in everyday life. Chicago: University of Chicago Press, 1997.

COELHO, M. C.; PARDO, J. O pátio de recreio: interação, “bullying” e gramáticas emocionais de vitimização. Dilemas: Revista de Estudos de Conflito e Controle Social, v. 11, n. 3, p. 533-561, set./dez. 2018

COELHO, M. C.; REZENDE, C. (org.). Cultura e sentimentos: ensaios em antropologia das emoções. Rio de Janeiro: Contra Capa, 2011.

CRAPANZANO, V. Réflexions sur une anthropologie des émotions. Terrain, n. 22, p. 109-117, 1994.

CUNHA, F. "Penosidade de fronteira”: perspectivas de governo, de gestão e de invenção da fronteira. 2017. Trabalho apresentado. Seminário Permanente Gênero e Territórios de Fronteira, Núcleo de Estudos de Gênero Pagu, Unicamp, Campinas, 2017.

DIAS, G. Tactics of border crossing movement: exploring the mobility of Brazilians through the Schengen and UK airspace. Ambivalências, v. 3, n. 5, p. 216-247, jan./jun. 2015.

DUARTE, L. F. D. A outra saúde... mental, psicossocial, físico-moral?. In: ALVES, P. C.; MINAYO, M. C. de S. (org.). Saúde e doença: um olhar antropológico. Rio de Janeiro: Editora Fiocruz, 1994. p. 83-90.

DUARTE, L. F. D. Investigação antropológica sobre doença, sofrimento e perturbação: uma introdução. In: DUARTE, L. F. D.; LEAL, O. F. (org.). Doença, sofrimento, perturbação: perspectivas etnográficas. Rio de Janeiro: Editora Fiocruz, 1998. p. 9-27.

ELIAS, N. La soledad de los moribundos. México: Fondo de Cultura Económica, 1989.

FASSIN, D. Humanitarian reason: a moral history of the present. Berkeley: University of California Press, 2011.

FONSECA, C. A morte de um gigolô: fronteiras da transgressão e sexualidade nos dias atuais. PISCITELLI, A.; GREGORI, M. F.; CARRARA, S. (org.). Sexualidades e saberes: convenções e fronteiras. Rio de Janeiro: Garamond, 2004. p. 257-281.

FOUCAULT, M. Em defesa da sociedade. São Paulo: Martins Fontes, 2008. 
GRIMSON, A. Los procesos de fronterización: flujos, redes e historicidad. In: GARCÍA, C. (ed.). Fronteras: territorios y metáforas. Medellín: Hombre Nuevo, 2003. p. 15-34.

GUEDES, A. O trecho, as mães e os papéis: etnografia de movimentos e durações no norte de Goiás. São Paulo: Garamond, 2013.

GUERRERO, R. et al. El sistema de salud en Colombia. Salud Pública de México, v. 53, supl. 2, p. 144-155, 2011.

HARAWAY, D. A partilha do sofrimento: relações instrumentais entre animais de laboratório e sua gente. Horizontes Antropológicos, Porto Alegre, ano 17, n. 35, p. 27-64, 2011.

LE BRETON, D. Por una antropología de las emociones. Revista Latinoamericana de Estudios sobre Cuerpos, Emociones y Sociedad, año 4, n. 10, p. 69-79, 2013.

LEVINO, A.; CARVALHO, E. de. Análise comparativa dos sistemas de saúde da tríplice fronteira: Brasil/Colômbia/Peru. Revista Panamericana de Salud Pública, v. 30, n. 5, p. 490-500, 2011.

MARTIN, E. The potentiality of ethnography and the limits of Affect Theory. Current Anthropology, v. 54, supl. 7, p. S149-S158, 2013.

MARTINS, J. de S. Fronteira: a degradação do Outro nos confins do humano. São Paulo: Hucitec, 1997.

MAUSS, M. A expressão obrigatória dos sentimentos. In: CARDOSO DE OLIVEIRA, R. (org.). Marcel Mauss: antropologia. São Paulo: Ática, 1979. p. 147-153.

MENEZES, R. Em busca da boa morte: antropologia dos cuidados paliativos. Rio de Janeiro: Garamond: Editora Fiocruz, 2004.

OLIVAR, J. M. Performatividades governamentais de fronteira: a produção do Estado e da fronteira através das políticas de tráfico de pessoas na Amazônia brasileira. Ambivalências, v. 3, n. 5, p. 149-182, jan./jun. 2015.

OLIVAR, J. M. Género, dinero y fronteras amazónicas: la "prostitución" en la ciudad transfronteriza de Brasil, Colombia y Peru. Cadernos Pagu, n. 51, 2017. el75115.

PISCITELLI, A. Trânsitos: brasileiras nos mercados transnacionais do sexo. Rio de Janeiro: Eduerj, 2013.

PISCITELLI, A. Sexual economies, love and human trafficking - new conceptual issues. Cadernos Pagu, n. 47, 2016. e16475.

REZENDE, C.; COELHO, M. C. Antropologia das emoções. Rio de Janeiro: Editora FGV, 2010. 
RUBIN, G. El tráfico de mujeres: notas sobre la "economía política" del sexo. Nueva Antropología, v. 8, n. 30, p. 95-145, 1986.

SAFATLE, V. O circuito dos afetos. São Paulo: Cosac Naify, 2015.

SAHLINS, M. Islands of history. Chicago: The University of Chicago Press, 1985.

SERJE, M. El revés de la nación: territorios salvajes, fronteras y tierras de nadie. Bogotá: Universidad de los Andes, 2005.

SKOGGARD, I.; WATERSTON, A. Introduction: toward an anthropology of affect and evocative ethnography. Anthropology of Consciousness, v. 26, n. 2, p. 109-120, 2015.

SONTAG, S. AIDS e suas metáforas. São Paulo: Companhia das Letras, 1989.

STRATHERN, M. Partial connections. Sabage: Rowman and Littlefield, 1991.

TAUSSIG, M. Xamanismo, colonialismo e o homem selvagem. São Paulo: Paz e Terra, 1993.

TURNER, F. J. Frontier, history and section: three essays. Albuquerque: University of New Mexico Press, 1993.

ZELIZER, V. The purchase of intimacy. Princeton: Princeton University Press, 2005.

Recebido: 29/05/2018 Aceito: 05/02/2019 | Received:5/29/2018 Accepted: 2/5/2019 